\title{
The effects of Dried Guava Waste and Dried Olive Cake as Substitutes for Alfalfa on Rabbit Farm Profit
}

\author{
Noha M. Wahed ${ }^{1 *}$, Sanad T. Attalah², Ragab A. Darwish ${ }^{1}$, Mohammed M. Fouda $^{1}$ \\ ${ }^{1}$ Department of Husbandry and Development of Animal Wealth, Faculty of Veterinary Medicine, Mansoura University, Mansoura, Egypt, P.O. \\ 35516 \\ ${ }^{2}$ Department of Animal Husbandry, Faculty of Veterinary Medicine, Alexandria University, Alexandria, Egypt.
}

\section{ARTICLE HISTORY}

Received: 16.11 .2019

Revised: 09.12.2019

Accepted: 10.12.2019

Address correspondence to Noha M. Wahed; Tel: +201020507879;

E-mail: nohawahed411@gmail.com

\section{ABSTRACT}

\begin{abstract}
Objectives: To evaluate the effects of adding dried guava waste and dried olive cake as substitution of alfalfa in diet on rabbit farm profits.

Design: Randomized controlled experimental study.

Animals: Thirty-six Hypluse white rabbits at the age of 33 days with an average body weight of $696.6 \mathrm{~g}$.

Procedures: Rabbits were allocated into four groups of nine animals each. Group 1 (Control group) was fed on a basal rabbit diet. Group 2 was fed on a diet containing $5 \%$ dried guava waste (DGW) as a substitute for alfalfa, Group 3 which was fed on a diet containing 5\% dried olive cake (DOC) as a substitute for alfalfa, and Group 4 which received a diet containing combination of both $5 \%$ DGW and $5 \%$ DOC as a substitute for alfalfa.

Results: The addition of 5\% DGW and 5\% DOC in diets of rabbits as a substitute for alfalfa resulted in improvements in body weights of animals when compared to the basal diets, whereas the inclusion of the two materials in the diet of rabbits lowered the body weights of animals. The feed intake in group (two and three) was lower than that of the control group. Groups (two and three) showed lower values of feed costs, total variable costs and higher total return, and thus had higher values of profits when compared to the control group. Group four showed higher total variable costs and total costs, while the total return was the lowest and consequently the profit was the lowest also.

Conclusion and clinical relevance: The addition of either 5\% DGW or DOC in diets of rabbits to substitute a portion of alfalfa appeared satisfactory for rabbit farm profit as their profit were higher than control group by 5.37 and 11.74 LE respectively, while their combination did not appear to be useful and therefore was not recommended.
\end{abstract}

Keywords: Dried guava waste, Dried olive cake, Profit.

\section{INTRODUCTION}

Rabbits are characterized by a small body size, short generation interval, rapid growth and reproductive rates with a high conversion rate of feed into body weight. They are known to give meat with a good quality protein with low-fat and high mineral content. Their meat is nearly of the same nutritive value as beef meat and comparable to that of broiler chicken with good meat-to-bone ratio. All previous characters made rabbits a suitable small species for solving the problem of meat shortage in Egypt, particularly on the level of the small-scale farmers [1].

The continual raise in costs of conventional feed resources that are used in the formation of livestock feeds forced researchers to find solutions of feed shortage by improving the conventional sources and investigating agricultural and agro-based industrial by- products which are considered non-conventional feed resources [2].
Dried guava wastes (DGW) is a non-conventional feed resource that has a high nutritive value with high-fiber content, suggesting that it has a considerable potential value as rabbit feed. Rabbits need diets with high-fiber content when they are compared with other simple stomach animals and poultry. Improving guava waste value can be achieved via developing environment-friendly technologies that can turn waste into new food ingredients or alternative products [3].

Mediterranean area is characterized by a high cultivation rate of olive, where the oil derived from olive is taken as dietary food. Considerable amount of olive industry by-product called olive cake is produced during the extraction of oil from olives. The dried olive cake (DOC) has a particular chemical composition that makes it a valuable feed resource for various species, particularly ruminants and rabbits [4]. 
DGW alone for growing rabbits diet and DOC for broiler diet provided significant effect on growth, digestibility, health and carcass characteristics [16\&17].

Therefore, this study is established to evaluate the effects of adding DGW or DOC and or both of them in the diet of rabbit to substitute alfalfa on the profit of the rabbit farms.

\section{MATERIAL AND METHODS}

\subsection{Animals}

Thirty six apparently healthy weaned rabbits of Hypluse breed, 33 days old with an average live body weight of 696.6 $\mathrm{g}$, were randomly distributed into four experimental groups (9 rabbits in each group). All animals were kept under a similar environmental condition in windowed rabbitry and were housed in galvanized batteries $(30 \mathrm{~cm} \mathrm{~L} \mathrm{x} 40 \mathrm{~cm} \mathrm{~W} \times 40$ $\mathrm{cm} \mathrm{H}$ ) provided with feeders and drinkers, where food and fresh water were supplied ad-libitum.

\subsection{Experimental diets}

All experimental diet rations were formulated as pelleted form. Two non-conventional feed resources were used in this study namely dried guava waste (DGW) and dried olive cake (DOC), which were incorporated into diets of the animals as a substitute for a part of alfalfa in basal diet formula.

The non-conventional feed resources used in this study were purchased from a specialized factory in drying the nonconventional feed resources. A sample of both DGW and DOC were taken for the estimation of their chemical composition.

\subsection{Experimental design}

The rabbits were distributed- in groups of nine- into four experimental groups as follows. 1- Group one (Control group): This group was fed on a basal rabbit diet. 2- Group two: This group was fed on a diet supplied with $5 \%$ DGW as a substitute for a portion of alfalfa. Group three- This group was fed on diet supplied with $5 \%$ DOC as a substitute for a portion of alfalfa. and 4- Group four- this group was fed on a diet supplied with a combination of both $5 \%$ DGW and $5 \%$ DOC as a substitute for a portion of alfalfa.

\subsection{Data collection}

Data were classified according to the methods implied by Atallah [5] and Omar [6].

(1) Production resources: It included the number of weaned rabbits, feed amount per animal, , body weight, average body weight of rabbit at marketing, marketing price per $\mathrm{kg}$ meat and droppings.
(2) Production costs: It included fixed costs and variable costs. For the fixed costs, the depreciation rates were calculated for the equipments on five year periods and the rent used as it is according to the method described by Durrani [7]. The variable costs represented the values of weaned rabbits, drugs, veterinary supervision, feed cost, labor cost, electricity and the transportation and miscellaneous costs [8] and [9].

(3) Production returns: It included the returns from total live body weight sales and droppings sales according to the market prices during the time of the study.

\subsection{Statistical analysis}

Data were analyzed using General linear model (repeated measures) to detect effect of time on (Body weights and feed amount), the other data analyzed by One way ANOVA. The calculations that used in analysis according to the methods implied by Atallah [5]

\section{RESULTS}

In table (1), body weights of rabbits are presented. The body weights of rabbits revealed a significant difference between groups. The supplementation of either $5 \%$ DGW or $5 \%$ DOC in diets of rabbits resulted in a significant increase in body weights of rabbits when compared to the control group fed on the basal diets. The body weights of animals fed on diets containing both of 5\% DGW and 5\% DOC were significantly lower than that of the control group. The higher body weights in all groups were observed in animals of group three.

In table (2), weekly feed intake (gm) and total feed intake $(\mathrm{kg})$ revealed a significant difference between groups of rabbits. In the first week, the group which was fed on the basal diet ( $G$ one) showed the lowest amount of feed intake. In the second week, rabbits which were fed on diets supplied with 5\% DGW (G two) showed the highest level of feed intake whereas the rabbits which were fed on diets containing both 5\% DGW and 5\% DOC (G four) showed the lowest level of feed intake. In the third week, $G$ two displayed the lowest feed intake, and $G$ four displayed the highest amount of feed intake. In the fourth week, $G$ two showed the lowest amount of feed intake and $G$ one showed the highest. In the fifth week, $G$ one (fed on basal diets) had the highest amount for feed intake and $G$ four had the lowest amount. In the sixth week, $G$ one showed the highest amount of feed intake and $G$ four displayed the lowest amount. Whereas in the seventh week, $G$ one had the highest amount and $G$ three had the lowest amount of feed intake. The total feed intake was lower in all groups ( $G$ two, $G$ three \& $G$ four) when compared to that of the control group ( $\mathrm{G}$ one).

In table (3), feed, drug and veterinary supervision costs revealed a significant difference between groups. Feed cost was lower in $G$ three and $G$ two than control group (G one).G four showed the highest level of drug costs. $G$ three displayed the lowest level of veterinary supervision. While, labor, miscellaneous and rabbit costs did not differ significantly between groups of rabbits. 
In table (4), total variable and total costs revealed a significant difference between groups. $G$ three showed the lowest levels of total variable costs followed by $G$ two and $G$ one whereas; the highest level was displayed by rabbits in $\mathrm{G}$ four. Whereas, values of total fixed costs (rent and equipment costs) showed no significant differences between groups.

In table (5), marketing sales, total return and net profit showed a significant difference between groups. G three showed the highest value of marketing sales, followed by $G$ two, whereas $G$ four displayed the lowest. $G$ three showed the highest levels of total return and net profit followed by $G$ two and $G$ one while $G$ four showed the lowest levels.

In table (6), collective efficiency measures revealed a significant difference between groups. The highest levels were shown by $\mathrm{G}$ three followed by $\mathrm{G}$ two, $\mathrm{G}$ one, while the lowest level was shown by $\mathrm{G}$ four.

Table 1: The effect of addition of 5\% DGW and 5\% DOC as a substitute for a portion of alfalfa in the diet of rabbit on body weights (gm) of rabbits (Mean $\pm \mathrm{SD}$ ).

\begin{tabular}{|c|c|c|c|c|c|c|c|c|}
\hline \multirow[b]{2}{*}{ Group } & \multicolumn{8}{|c|}{ Time post-treatment (Week) } \\
\hline & 0 & 1 & 2 & 3 & 4 & 5 & 6 & $\begin{array}{l}7 \\
\text { (Marketing } \\
\text { weight) }\end{array}$ \\
\hline G1 & $700 \pm 12.6$ & $878.6 \pm 46.1^{B C}$ & $1050 \pm 64.3^{B}$ & $1179.3 \pm 73.1^{C}$ & $1394.3 \pm 78.9^{c}$ & $1594.3 \pm 71.6^{\mathrm{CD}}$ & $1804.3 \pm 76.5^{C D}$ & $2009.3 \pm 80.9^{C D}$ \\
\hline G2 & $697.1 \pm 8.6$ & $872.9 \pm 30.8^{B C}$ & $1054.3 \pm 45.8^{B}$ & $1226.4 \pm 51.5^{\mathrm{BC}}$ & $1451.4 \pm 50.3^{\mathrm{ABC}}$ & $1661.4 \pm 52.4^{\mathrm{ABC}}$ & $1890.7 \pm 68^{\mathrm{AB}}$ & $2110.7 \pm 49.9^{B}$ \\
\hline G3 & $697.1 \pm 8.6$ & $921.4 \pm 31.6^{\mathrm{A}}$ & $1130 \pm 56.3_{\mathrm{A}}$ & $1297.1 \pm 64.3^{\mathrm{A}}$ & $1502.1 \pm 70.7^{A}$ & $1732.9 \pm 82.7^{A}$ & $1962.9 \pm 81.4^{\mathrm{A}}$ & $2202.9 \pm 98.9^{A}$ \\
\hline G4 & $691.7 \pm 6.8$ & $843.3 \pm 19.7^{c}$ & $982.5 \pm 23.8^{c}$ & $116.7 \pm 13.7^{D}$ & $1306.7 \pm 27.5^{D}$ & $1511.7 \pm 19.4^{\mathrm{E}}$ & $1706.7 \pm 25.7^{\mathrm{E}}$ & $1926.7 \pm 28.9^{\mathrm{DE}}$ \\
\hline$P$ value & NS & 0.0001 & 0.0001 & 0.0001 & 0.0001 & 0.0001 & 0.0001 & 0.0001 \\
\hline
\end{tabular}

Time: Significant at $(P<0.0001)$; Time * Treatment: Significant at $(P<0.0001)$.

Means within the same column of different capital subscript litters are significantly different at $(P<0.0001)$.

NS = Non significant. (G1): control group, (G2) fed on diet with 5\% DGW, (G 3) fed on diet with 5\% DOC as (G 4) received diet contain combination of $5 \%$ DGW and $5 \%$ DOC as substitution of alfalfa.

Table 2. The effect of addition of 5\% DGW and 5\% DOC as a substitute for a portion of alfalfa in the diet of rabbit on weekly (gm) and total feed intake $(\mathrm{Kg})$ of rabbits (Mean $\pm \mathrm{SD})$.

\begin{tabular}{|c|c|c|c|c|c|c|c|c|}
\hline & \multicolumn{8}{|c|}{ Time post-treatment (Week) } \\
\hline Group & 1 & 2 & 3 & 4 & 5 & 6 & 7 & Total \\
\hline G1 & $260 \pm 6.5^{B}$ & $480.7 \pm 8.9^{B}$ & $425.9 \pm 5.9^{B}$ & $355 \pm 6.5^{A}$ & $320 \pm 11.9^{A}$ & $340 \pm 11.18^{A}$ & $330 \pm 12.9^{A}$ & $2.51 \pm 0.02^{\mathrm{A}}$ \\
\hline G2 & $297.9 \pm 4.9^{A}$ & $502.1 \pm 9.5^{\mathrm{A}}$ & $387.1 \pm 8.1^{\mathrm{D}}$ & $285 \pm 7.1^{\mathrm{D}}$ & $270 \pm 10.8^{\mathrm{BC}}$ & $305 \pm 11.9^{B}$ & $295 \pm 10.8^{B}$ & $2.34 \pm 0.03^{C}$ \\
\hline G3 & $293.6 \pm 7.5^{\mathrm{A}}$ & $457.1 \pm 5.7^{C}$ & $255 \pm 6.5^{\mathrm{A}}$ & $305 \pm 10.8^{c}$ & $290 \pm 11.5^{\mathrm{AB}}$ & $290 \pm 11.5^{c}$ & $280 \pm 7.1^{C}$ & $2.17 \pm 0.04^{\mathrm{D}}$ \\
\hline G4 & $295.8 \pm 5.8^{A}$ & $460.8 \pm 7.4^{c}$ & $550.8 \pm 7.4^{\mathrm{A}}$ & $300 \pm 7.1^{c}$ & $252 \pm 110.2^{\mathrm{BC}}$ & $280 \pm 13^{C D}$ & $300 \pm 15.2^{B}$ & $2.44 \pm 0.11^{B}$ \\
\hline$P$ value & 0.001 & 0.0001 & 0.0001 & 0.0001 & 0.0001 & 0.0001 & 0.0001 & 0.0001 \\
\hline
\end{tabular}

Time: Significant at $(P<0.0001)$; Time * Treatment: Significant at $(P<0.0001)$.

Means within the same column of different capital subscripts litters are significantly different at $(P<0.0001)$.

(G1): control group, (G2) fed on diet with $5 \%$ DGW, (G 3) fed on diet with $5 \%$ DOC as (G 4) received diet contain combination of $5 \%$ DGW and $5 \%$ DOC as substitution of alfalfa. 
Table 3. The effect of addition of $5 \%$ DGW and $5 \%$ DOC as a substitute for a portion of alfalfa in the diet of rabbit on feed, drugs, veterinary supervision, miscellaneous and rabbit costs (Mean \pm SD).

$\begin{array}{lllllll}\text { Group } & \begin{array}{c}\text { Feed costs } \\ (\mathrm{LE} / \mathrm{Kg})\end{array} & \begin{array}{c}\text { Drug costs } \\ (\mathrm{LE})\end{array} & \begin{array}{c}\text { Veterinary supervision } \\ \text { costs (LE) }\end{array} & \begin{array}{c}\text { Labor cost } \\ \text { (LE) }\end{array} & \begin{array}{c}\text { Miscellaneous } \\ \text { cost (LE) }\end{array} & \begin{array}{c}\text { Rabbits cost } \\ \text { (LE/Rabbit) }\end{array} \\ \text { G1 } & 14.32 \pm 0.1^{\mathrm{A}} & 6.29 \pm 0.2^{\mathrm{B}} & 6.19 \pm 0.2^{\mathrm{A}} & 5 & 8 & 45 \\ \text { G2 } & 13.02 \pm 0.2^{\mathrm{C}} & 6.43 \pm 0.2^{\mathrm{B}} & 6.27 \pm 0.3^{\mathrm{A}} & 5 & 8 & 45 \\ \text { G3 } & 12.11 \pm 0.2^{\mathrm{E}} & 6.29 \pm 0.2^{\mathrm{B}} & 5.97 \pm 0.2^{\mathrm{B}} & 5 & 8 & 45 \\ \text { G4 } & 13.37 \pm 0.7^{\mathrm{B}} & 7.67 \pm 0.1^{\mathrm{A}} & 6.18 \pm 0.2^{\mathrm{A}} & 5 & 8 & 45 \\ \boldsymbol{P} \text { value } & 0.0001 & 0.0001 & 0.01 & \mathrm{NS} & \text { NS } & \text { NS }\end{array}$

Means within the same column of different capital subscript litters are significantly different at $(P<0.01)$ and $(P<0.0001)$

NS = Non significant. (G1): control group, (G2) fed on diet with 5\% DGW, (G 3) fed on diet with $5 \%$ DOC as (G 4) received diet contain combination of $5 \%$ DGW and $5 \%$ DOC as substitution of alfalfa.

Table 4: The effect of addition of 5\% DGW and 5\% DOC as a substitute for a portion of alfalfa in the diet of rabbit on total variable, equipment, rent, total fixed and total costs (Mean $\pm S D$ ).

$\begin{array}{llllll}\text { Group } & \text { Total variable cost } & \text { Equipments } & \text { Rent cost } & \text { Total fixed cost } & \text { Total costs } \\ & (\mathrm{LE}) & \text { Cost (LE) } & (\mathrm{LE}) & \text { (LE) } & \text { (LE) } \\ \text { G1 } & 84.79 \pm 0.3^{\mathrm{B}} & 6 & 11 & 17 & 101.79 \pm 0.3^{\mathrm{B}} \\ \text { G2 } & 83.62 \pm 06^{\mathrm{C}} & 6 & 11 & 17 & 100.62 \pm 0.6^{\mathrm{C}} \\ \text { G3 } & 82.11 \pm 0.3^{\mathrm{DE}} & 6 & 11 & 17 & 99.11 \pm 0.3^{\mathrm{DE}} \\ \text { G4 } & 85.22 \pm 0.7^{\mathrm{A}} & 6 & 11 & 17 & 102.22 \pm 0.7^{\mathrm{A}} \\ \boldsymbol{P} \text { value } & 0.0001 & \mathrm{NS} & \mathrm{NS} & \mathrm{NS} & 0.0001\end{array}$

Means within the same column of different capital superscripts litters are significantly different at $(P<0.0001)$.

NS = Non significant. G1): control group, (G2) fed on diet with $5 \%$ DGW, (G 3) fed on diet with $5 \%$ DOC as (G 4) received diet contain combination of $5 \%$ DGW and $5 \%$ DOC as substitution of alfalfa

Table 5: The effect of addition of 5\% DGW and 5\% DOC as a substitute for a portion of alfalfa in the diet of rabbit on marketing sales, dropping price, total return and net profit (Mean $\pm \mathrm{SE}$ ).

$\begin{array}{lcccc}\text { Group } & \begin{array}{c}\text { Marketing sales } \\ \text { (LE) }\end{array} & \begin{array}{c}\text { Dropping price } \\ \text { (LE) }\end{array} & \begin{array}{c}\text { Total return } \\ \text { (LE) }\end{array} & \begin{array}{c}\text { Net profit } \\ \text { (LE) }\end{array} \\ \text { G1 } & 90.42 \pm 3.6^{\mathrm{C}} & 10 & 100.42 \pm 3.6^{\mathrm{C}} & -1.37 \pm 3.5^{\mathrm{D}} \\ \text { G2 } & 94.98 \pm 2.2^{\mathrm{B}} & 10 & 104.98 \pm 2.2^{\mathrm{B}} & 4.36 \pm 2.6^{\mathrm{C}} \\ \text { G3 } & 99.13 \pm 4.5^{\mathrm{A}} & 10 & 109.13 \pm 4.5^{\mathrm{A}} & 10.02 \pm 4.4^{\mathrm{AB}} \\ \text { G4 } & 86.7 \pm 1.3^{\mathrm{D}} & 10 & 96.7 \pm 1.3^{\mathrm{D}} & -5.51 \pm 1.3^{\mathrm{E}} \\ \text { P value } & 0.0001 & \text { NS } & 0.0001 & 0.0001\end{array}$

Means within the same column of different capital subscript litters are significantly different at $(P<0.0001)$.

NS = Non significant. G1): control group, (G2) fed on diet with 5\% DGW, (G 3) fed on diet with 5\% DOC as (G 4) received diet contain combination of $5 \%$ DGW and $5 \%$ DOC as substitution of alfalfa.

Table 6: The effect of addition of 5\% DGW and 5\% DOC as a substitute for a prtion of alfalfa in the diet of rabbit on collective efficiency measures (Mean \pm SD).

\begin{tabular}{|c|c|c|c|c|}
\hline Group & $\begin{array}{l}\text { Total return/ total } \\
\text { costs (\%) }\end{array}$ & $\begin{array}{l}\text { Total return / total variable costs } \\
\qquad(\%)\end{array}$ & Net profit/total costs (\%) & $\begin{array}{l}\text { Net profit /total variable costs } \\
\text { (\%) }\end{array}$ \\
\hline G1 & $98.65 \pm 3.5^{\mathrm{D}}$ & $118.43 \pm 0.04^{\mathrm{D}}$ & $-1.35 \pm 3.5^{\mathrm{D}}$ & $-1.62 \pm 4.2^{D}$ \\
\hline G2 & $104.34 \pm 2.6^{c}$ & $125.56 \pm 0.03^{c}$ & $4.34 \pm 2.6^{c}$ & $5.23 \pm 3.1^{c}$ \\
\hline G3 & $110.11 \pm 4.5^{\mathrm{AB}}$ & $132.9 \pm 0.05^{\mathrm{AB}}$ & $10.11 \pm 4.5^{\mathrm{AB}}$ & $12.19 \pm 5.4^{\mathrm{AB}}$ \\
\hline G4 & $94.6 \pm 1.2^{\mathrm{E}}$ & $113.47 \pm 0.02^{E}$ & $-5.39 \pm 1.2^{\mathrm{E}}$ & $-6.48 \pm 1.4^{E}$ \\
\hline$P$ value & 0.0001 & 0.0001 & 0.0001 & 0.0001 \\
\hline
\end{tabular}

Means within the same column of different capital subscript litters are significantly different at $(P<0.0001)$.

G1): control group, (G2) fed on diet with 5\% DGW, (G 3) fed on diet with 5\% DOC as (G 4) received diet contain combination of 5\% DGW and $5 \%$ DOC as substitution of alfalfa 


\section{DISCUSSION}

Feed is the main component of the input cost, as it constitutes about $70 \%$ of the total production cost therefore having great impact on farm operation profitability. In the present study feed cost was decreased by using nonconventional feed resources in groups of rabbits. The body weight of rabbits fed on diets supplied with $5 \%$ DGW or $5 \%$ DOC as a substitute of a part of alfalfa was significantly higher than that of animals fed on basal diets (control group). The difference in body weight of the animals may be attributed to better digestibility of diets containing DGW or DOC than basal diet as DGW and DOC contain more digestible fibers than alfalfa. These results agree with those of previous work which showed that the inclusion of dried guava waste improved body weights in rabbits [16].. Similar experiments on broiler chicken showed that body weights of broiler chicken fed on diets contain $10 \%$ dried olive cake were higher than that of control birds [17, 18]. While combining both of DGW and DOC in one feed lowered body weights of animals. This reduction in weights of rabbits may be attributed to that increasing the fibrous content of the feed extensively can decrease the digestibility and hence the body weight.

The feed intake differed significantly between groups of rabbits received diets with different ingredients. The groups of rabbits that received 5\% DGW and 5\% DOC (G two, G three) showed lower feed intake than the control group. This difference in feed intake may be attributed to the improved digestibility of nutrients in diets supplied with DGW and DOC. The reduction of feed intake in these groups despite the fact that they showed enhanced body weights could reflect the fact that these diets gave the same nutrient value compared to the higher amount of basal diet. These results agree with results of previous work that stated that addition of DOC in broiler chicken diets up to $10 \%$ of the diet decreased feed intake $[17,19]$. Similar finding was also reported by previous research showing that the addition of DGW in rabbits diet lowered feed intake when compared to animals fed on basal diets [16].

Feed cost was lower in treated groups ( $G$ two, G three and $G$ four) than control group. This reduction in feeding cost could be attributed to the lower feed intake of these groups and the lower costs of DGW and DOC than alfalfa. The drug and veterinary supervision costs were higher in $G$ four. The increase in drug and veterinary supervision costs paralleled the increase in rates of infection and mortalities which was also highest in this particular group. This finding may be attributed to the lower level of immunity of this group. Miscellaneous, rabbit and labor costs were fixed in all groups. These results are also in the same line with previous research. The addition of DGW up to $20 \%$ in rabbit diets has been shown to decrease the feed costs [16]. Similarly, the addition of DOC to the diets of broiler chicken at the level of $10 \%$ was found to decrease feed costs $[17,19]$.

The rent and equipment costs are fixed cost therefore did not differ between groups. However, the reason why the total variable costs were lower in $G$ two and $G$ three than the control group could be their lower feed, drugs and veterinary supervision costs. Also the reason why $G$ four showed the highest total variable cost compared to the control group could be the higher costs of drugs and veterinary supervision of this group. These results agree with those reported previously [16-19].

The marketing sales were higher in $\mathrm{G}$ two and $\mathrm{G}$ three when compared to the control group, and this might be attributed to their higher body weights. While, the reason why $G$ four showed the lowest marketing sales could be their lower body weights. The results reported by the current work suggest that the total return and consequently the profit of rearing rabbits are increased in $G$ two and $G$ three and decreased in $G$ four when compared to the control group.

The percentages of total return to total cost, net profit to total cost, net profit to total return were higher in $\mathrm{G}$ two and $G$ three when compared to both control group and $G$ four. These results reveal that the inclusion of DGW or DOC each one alone in diet of rabbits was the most profitable when compared with either the inclusion of both of them or the basal diet. These findings agree with those reported by previous research work $[4,9,15-20]$ indicating that the use of non-conventional feed resources could decrease the overall production costs and improve farm profit.

\section{Conclusion}

Substitution of a portion of alfalfa in diets of rabbit at a level of $5 \%$ with DGW or DOC resulted in improvements of farm economic efficiency and high profit. However, the supplementation of both of 5\% DGW and DOC in the same diet was not effective and was therefore not recommended.

\section{Conflict of interest}

The authors declare that there is no any conflict of interest in the current research work.

\section{Research Ethics Committee Permission}

The current research work was permitted to be executed according to Standards of Research Ethics Committee, Faculty of Veterinary Medicine, Mansoura University.

\section{Authors' contribution}

Noha M. Wahed conducted the experiment and analytical procedures; Sanad T. Attalah performed statistical analysis and helped in writing the manuscript; Ragab $A$. Darwish helped in writing the manuscript and Mohammed M. Fouda edited the manuscript.

\section{REFERENCES}

[1]Baruwa O. Profitability and constraints to rabbit production under tropical conditions in Nigeria. J Anim Sci 2014;5:83-8.

[2]Hamzat R, Adejinmi O, Babatunde B, Olubamiwa O. Effect of dietary inclusion of Kolapod husk on performance and carcass characteristics of cockerels. Proceedings of the $30^{\text {th }}$ Annual Conference of the Nigerian Society of Animal Production, University of Nigeria Nsukka, Nigeria Editors 
Onah DN, Ani AO, Ugwu SOC, Ezeokonkwo RC, Ihedioha JI and Chah KF 18th2005. p. 224.7-

[3]Nour V, Panaite TD, Ropota M, Turcu R, Trandafir I, Corbu AR. Nutritional and bioactive compounds in dried tomato processing waste. CyTA-Journal of Food. 2018;16:222-9.

[4]Dal Bosco A, Mourvaki E, Cardinali R, Servili M, Sebastiani B, Ruggeri S, et al. Effect of dietary supplementation with olive pomaces on the performance and meat quality of growing rabbits. Meat sci 2012;92:783-8.

[5]Atallah ST. Economic and productive efficiency of veterinary management in dairy farms. Ph. D. Thesis. Veterinary Medicine, University of Alex. Egypt. 1997.

[6]Omar MAE. Economic study on the productive and reproductive efficiency of dairy farms in relation to veterinary management. Ph.D. Faculty of Veterinary Medicine. Zagazig University, 2009.

[7]Durrani MF. Production performance and economic appraisal of commercial layers in district Chakwal: NWFP Agricultural University, Peshawar-Pakistan; 2002.

[8]Atallah ST. Study the economic and productive efficiency of some broiler farms in relation to ration constituents. Minoufyia Vet J 2000;1:6983.

[9]Bano R, Shah H, Sharif M, Akhtar W. Profitability index and capital turn over in open house broilerfarming: acase study of district Rawalpindi. Pak J Agric Res 2011;24:75-81.

[10]New JC. Costs of veterinary services and vaccines/drugs used for prevention and treatment of diseases in 60 Tennessee cow-calf operations (1987-1988). J Am Vet Med Assoc 1991;198:1334-40.

[11]Atallah ST. Effect of cattle diseases on reproductive, productive and economic efficiency of dairy farms. Minufiya Vet J 2004;1:99-145.

[12]Rosegrant MW, Msangi S, Ringler C, Sulser TB, Zhu T, Cline SA. International Model for Policy Analysis of Agricultural Commodities and Trade (IMPACT): Model description. Washington, D.C.: International Food Policy Research Institute. 2008.

[13] Muhammad DF. Production performance and economic appraisal of commercial layers in District Chakwal. Ph.D. Thesis. NWFP Agriculture University, Peshawar. 2002

[14]Lotfollahian $\mathrm{H}$, Hosseini SA. Evaluation of metabolizable energy values of some feeding stuffs. Pak J Biol Sci 2007;10:995-7.

[15]Rahimi I, Behmanesh R. Improve poultry farm efficiency in Iran: using combination neural networks, decision trees and data envelopment analysis (DEA). Int J Appl Operat Res 2012;2:69-84.

[16]Kamel ER, Abdel-Fattah F, El-Qaliouby HS, Mahmoud E. Response of New Zealand Rabbits to Diet Containing Guava Waste (Psidium Guaijava L.): 1. Effect on Growth Performance, Diet Digestibility and Economic Efficiency. Alex J Vet Sci 2016;50.

[17]Al-Harthi M, Attia Y. Effect of citric acid on the nutritive value of olive cake in broilers diets. Eur Poult Sci 2016a. 2016:1-14.

[18]De Blas J, Rodriguez CA, Bacha F, Fernandez R ,Abad-Guamán R. Nutritive value of co-products derived from olivecake in rabbit feeding. World Rabbit Sci 2015;23:255-62.

[19]Mehrez A, Mousa M. Growth performance of rabbits fed olive pulp in North Sinai. Asian J Anim Sci 2011;5:317-29.

[20]Ozung P, Oko OK, Agiang E, Eburu P, Evans E, Ewa C. Growth performance and apparent nutrient digestibility coefficients of weaned rabbits fed diets containing different forms of cocoa pod husk meal. Agr Food Sci Res 2017;4:8-19. 